\title{
Assessing the Potential of Biochar for Improving Soil Physical Properties and Tree Growth
}

\author{
Riziki Mwadalu $\left(\mathbb{D},{ }^{1,2}\right.$ Benson Mochoge $\mathbb{D D}^{1}$ and Benjamin Danga $\mathbb{D}^{1}$ \\ ${ }^{1}$ Kenyatta University, School of Agriculture and Enterprise Development, P.O. Box 43844-00100, Nairobi, Kenya \\ ${ }^{2}$ Kenya Forestry Research Institute, Central Highland Eco-Region Research Programme, P.O. Box 20412-00200, Nairobi, Kenya \\ Correspondence should be addressed to Riziki Mwadalu; zikiemwa@gmail.com
}

Received 24 April 2021; Revised 31 May 2021; Accepted 7 June 2021; Published 17 June 2021

Academic Editor: Maria Serrano

Copyright (C) 2021 Riziki Mwadalu et al. This is an open access article distributed under the Creative Commons Attribution License, which permits unrestricted use, distribution, and reproduction in any medium, provided the original work is properly cited.

\begin{abstract}
The effect of biochar on tree growth and soil physical properties as indicated in literature is still outstanding. Information on the effect of biochar on tree growth is limited, and the available literature has recorded conflicting results. Therefore, a field experiment using Casuarina equisetifolia (Casuarina) as the test crop under different biochar rates was conducted. Four biochar rates $\left(0,2.5,5.0\right.$, and $\left.7.5 \mathrm{tha}^{-1}\right)$ were used as treatments, each replicated three times. Generally, biochar-amended plots recorded higher Casuarina height, collar diameter, and diameter at breast height (DBH). The application of biochar at $7.5 \mathrm{tha}^{-1}$ resulted in higher Casuarina height of up to $20.2 \%$ compared to the control. On the contrary, application of biochar at $2.5 \mathrm{tha}^{-1}$ recorded higher collar diameter of up to $30.2 \%$ compared to the control. Generally, there was a decrease in soil bulk density with biochar application. Bulk density decreased linearly with increasing biochar application rates with biochar application rate of $7.5 \mathrm{t} \mathrm{ha}^{-1}$ recording the lowest bulk density $\left(0.99 \mathrm{~g} \mathrm{~cm}^{-3}\right)$. There was a decrease in bulk density of up to $25 \%$ compared to the control with the biochar application rate of $7.5 \mathrm{tha}^{-1}$. Biochar application rate of $7.5 \mathrm{tha}^{-1}$ also recorded the highest soil moisture content across the assessment periods. Biochar-amended plots recorded higher soil moisture content than the untreated control. There was increase in soil moisture content following biochar application of up to $108 \%$ with the application of biochar at $7.5 \mathrm{tha}^{-1}$ compared to the untreated control. The increase in soil moisture content with biochar application can be attributed to biochar's porous nature and large surface area. These results suggest that the use of biochar has the potential of enhancing Casuarina growth while enhancing soil physical properties by decreasing bulk density and enhancing soil moisture storage.
\end{abstract}

\section{Introduction}

Dwindling soil fertility is considered a severe bio-physical root cause of declining land productivity in sub-Saharan Africa [1]. The main factors contributing to soil fertility decline are losses of soil nutrients through soil erosion by wind, water, and leaching of $\mathrm{N}$ and $\mathrm{K}$. Loss of soil nutrients specifically due to erosion in African soils has been reported to range from 10 to $45 \mathrm{~kg}$ of NPK per hectare per year $[2,3]$. Soil fertility challenges coupled with frequent droughts in sub-Saharan Africa have led to massive crop failures thereby increasing the problem of food insecurity. Frequent and prolonged dry spells have become a characteristic of arid and semiarid lands (ASALs) in Kenya. As climate change unfolds, climate variability is expected to worsen [4] thus leading to more rising temperature and increasing rainfall uncertainty. A study by Herrero et al. [5] noted that temperature increase in Africa is between $3^{\circ} \mathrm{C}$ and $4^{\circ} \mathrm{C}$, roughly 1.5 times the global mean. The increase in temperature as highlighted by Ochieng et al and Herrero et al. $[4,5]$ are likely to lead to depressed and highly erratic rainfall thus hampering crop growth and tree growth for tree farmers. To address these challenges, studies have been conducted to come up with soil amendments that enhance soil fertility and improve soil physical characteristics while boosting soil moisture retention.

Among many technologies, the use of biochar has been reported to offer a cost-effective means of improving soil 
fertility and water-holding capacity of soils $[6,7]$. Biochar is a technology that has been reported to provide conditions suitable for plant growth by providing necessary nutrients for growth and development [8], reduced soil compaction through bulk density (BD) reduction and increase soil waterholding capacity. Biochar application as a soil amendment is motivated by its capacity to promote plant growth and altering soil physical and chemical properties [9]. Numerous studies have reported the benefits accrued to biochar as soil amendment especially for soil moisture storage and crop yield improvement worldwide [10-12] in agricultural landscapes. However, the effects of biochar on physicochemical soil properties and tree growth as indicated in literature are still limited.

Based on the above arguments, there was need to examine the effect of biochar on soil physical properties and tree growth on sandy soil in Coastal Kenya with Casuarina equisetifolia as the test crop. Casuarina is a major commercial tree species at the Kenyan Coast due to its fast growth and marketability. This study therefore addressed two specific objectives: (i) to determine the effect of biochar on Casuarina growth and (ii) to assess the effect of biochar on soil physical properties (soil moisture and BD). The results of this study are crucial to researchers and extension officers tasked to advise farmers on appropriate Casuarina tree farming approaches for optimum performance and productivity.

\section{Materials and Methods}

2.1. Study Site. A field experiment was conducted at the Kenya Forestry Research Institute (KEFRI) research site situated at Gede, Kilifi County in the coastal region of Kenya. The research site was situated at S 03.29480" E $039.99602^{\prime \prime}$. Kilifi county lies between latitude $2^{\circ} 20^{\prime}$ and $4^{\circ} 0^{\prime}$ South, and between longitude $39^{\circ} 05^{\prime}$ and $40^{\circ} 14^{\prime}$ [13]. The total land area of the county is roughly $12,609.7 \mathrm{~km}^{2}$, with a terrain that generally slopes towards the ocean. The mean annual rainfall ranges between $300 \mathrm{~mm}$ in the hinterland and 1,300 $\mathrm{mm}$ along the coastal belt of the County. Kilifi county has five agroecological zones (AEZs) categorized using annual rainfall, mean temperatures, vegetation, and humidity. As a result of high temperatures experienced in the county, there are high evaporation rates varying from $1,800 \mathrm{~mm}$ along the coastal strip to $2,200 \mathrm{~mm}$ in the hinterland. Approximately $50 \%$ of the land area in the county is arable, with maize and cassava being the key subsistence crops mainly grown by small-scale farmers. Other crops grown mostly by large-scale farmers as cash crops include coconuts, sisal, cashew nuts, and citrus fruits. The dominant soil type in Gede area where the experiment was conducted is arenosol.

2.2. Experimental Design. The study was conducted between October 2019 and October 2020. The experiment was set up using a randomized complete block design (RCBD) with four treatments replicated three times. Four biochar rates were used as treatments $\left(0,2.5,5.0\right.$, and $\left.7.5 \mathrm{tha}^{-1}\right)$. Biochar was prepared through pyrolysis of dried Prosopis juliflora branches at $450^{\circ} \mathrm{C}$ with 3 hours residence time. Plots of $12 \mathrm{~m}$ by $12 \mathrm{~m}$ were used for the experiment with Casuarina planting spacing of $2 \mathrm{~m}$ by $2 \mathrm{~m}$ and $3 \mathrm{~m}$ space between plots. Biochar was thoroughly mixed with the soil prior to transplanting the Casuarina seedlings to the field; seedlings of uniform height $(30 \mathrm{~cm})$ were used for the experiment establishment.

2.3. Casuarina Growth Assessment. Growth assessment was done quarterly for a period of 12 months. Height $(\mathrm{m})$ of Casuarina was measured using a grade rod, while diameter at ground level (DGL)/collar diameter $(\mathrm{cm})$ and diameter at breast height $(\mathrm{DBH})$ were measured using a Vernier calliper. Collar diameter was measured for 9 months. The DBH was measured 12 months after field establishment and was measured at $1.3 \mathrm{~m}$ above the ground. Each treatment had a total of 108 trees (36 per replicate) which were all measured and means per replicate for each treatment were used for computation and analysis.

2.4. Soil Sampling and Analysis. Determination of soil moisture was done at 3, 6, 9, and 12 months after experiment establishment (MAE). Soil moisture was determined gravimetrically to a depth of $20 \mathrm{~cm}$. BD was determined at 3 $\mathrm{MAE}$ and at $9 \mathrm{MAE}$ using the core ring method. Soil texture was determined using improved hydrometer method for soil particle sizes; $\mathrm{pH}$ and electro conductivity were determined using portable glass electrode; total $\mathrm{C}$ was determined using Walkley-Black method; total nitrogen was analysed using Kjeldahl method; available phosphorus and magnesium were analysed using UV spectrophotometer method; and potassium and calcium were determined using flame photometer method $[14,15]$. Soil moisture was determined gravimetrically using the following formula:

$$
W=\frac{(100 \mathrm{Mw})}{\mathrm{Ms}}
$$

where $W$ is the soil moisture content in \%, Ms is the dry mass of soil, Mw is the mass of water in soil.

For soil BD, the following formula was used:

$$
\mathrm{BD}\left(\mathrm{g} \mathrm{cm}^{-3}\right) \frac{\text { mass of soil }(\mathrm{g})}{\text { volume of soil }\left(\mathrm{cm}^{3}\right)} \text {. }
$$

2.5. Statistical Analysis. The data obtained from the field and laboratory were subjected to repeated measure analysis of variance (ANOVA) using $\mathrm{R}$ software (version 4.0.3) for windows at $95 \%$ confidence level to determine the level of significance accrued to the treatments applied. Means were separated using Tukey HSD test. Pearson's correlation was also done to determine exiting relationships between variables. Regression analysis was also undertaken using $\mathrm{R}$ software to determine the strength of existing linear relationships between variables. 
TABLE 1: Baseline soil and biochar characteristics for Casuarina field experiment.

\begin{tabular}{|c|c|c|}
\hline Parameter & Baseline soil status & Biochar characteristics \\
\hline $\mathrm{PH}$ & 6.65 & 8.7 \\
\hline $\mathrm{EC}(\mathrm{mS} / \mathrm{cm})$ & 0.052 & 1.39 \\
\hline Total C (\%) & 0.65 & 48 \\
\hline Total N (\%) & 0.06 & 0.84 \\
\hline Soil organic matter $(\%)$ & 1.12 & - \\
\hline $\mathrm{P}\left(\mathrm{mg} \mathrm{kg}^{-1}\right)$ & 1.8 & 26.6 \\
\hline $\mathrm{K}\left(\mathrm{mg} \mathrm{kg}^{-1}\right)$ & 62 & 1166.1 \\
\hline $\mathrm{Ca}\left(\mathrm{mg} \mathrm{kg}^{-1}\right)$ & 200 & 746 \\
\hline $\mathrm{Mg}\left(\mathrm{mg} \mathrm{kg}^{-1}\right)$ & 149 & 354 \\
\hline $\mathrm{Na}\left(\mathrm{mg} \mathrm{kg}^{-1}\right)$ & - & 989 \\
\hline Texture ( $90 \%$ sand, $6 \%$ clay, and $4 \%$ silt) & Sand & - \\
\hline Bulk density $\left(\mathrm{g} \mathrm{cm}^{-3}\right)$ & 1.3 & - \\
\hline $\mathrm{C} / \mathrm{N}$ ratio & - & 57 \\
\hline $\operatorname{CEC~}\left(\mathrm{cmol}_{(+)} \mathrm{kg}^{-1}\right)$ & - & 11.2 \\
\hline
\end{tabular}

TABLE 2: Casuarina mean height under different biochar application rates and assessment periods.

\begin{tabular}{lcccc}
\hline Seedling height \pm SE $(\mathrm{m})$ & \multicolumn{3}{c}{ Growth period (months) } \\
Treatment & 3 & 6 & $1.77 \pm 0.06 \mathrm{~b}$ & 12 \\
\hline Control & $0.75 \pm 0.04 \mathrm{~b}$ & $1.15 \pm 0.03 \mathrm{~b}$ & $2.77 \pm 0.07 \mathrm{~b}$ \\
Biochar 2.5 tons/ha & $0.89 \pm 0.09 \mathrm{a}$ & $1.42 \pm 0.13 \mathrm{a}$ & $2.18 \pm 0.17 \mathrm{a}$ & $3.24 \pm 0.27 \mathrm{a}$ \\
Biochar 5.0 tons/ha & $0.85 \pm 0.07 \mathrm{ab}$ & $1.36 \pm 0.17 \mathrm{ab}$ & $2.07 \pm 0.22 \mathrm{a}$ & $3.18 \pm 0.14 \mathrm{a}$ \\
Biochar 7.5 tons/ha & $0.89 \pm 0.06 \mathrm{a}$ & $1.43 \pm 0.07 \mathrm{a}$ & $2.13 \pm 0.14 \mathrm{a}$ & 3.19 \\
$f(3,8)$ & 3.02 & 3.95 & 0.05 & 7.21 \\
$p<0.05$ & 0.09 n.s. & 0.05 & 0.01 \\
\hline
\end{tabular}

Note: (i) values denoted by the same letter along the column are not significantly different at $p<0.05$, (ii) n.s. means not significant, and (iii) $n=12$.

\section{Results and Discussion}

3.1. Baseline Soil Status. The baseline soil status of the field experimental site was determined at the onset of the experiment as shown in Table 1 . The $\mathrm{pH}$ was neutral with low EC, total N, total C, SOM, available $\mathrm{P}$, exchangeable $\mathrm{Mg}$, and exchangeable $\mathrm{K}$ which is the characteristic of the coastal soils that have low inherent fertility [16]. The site however had adequate exchangeable $\mathrm{Ca}$ which is often adequate in Coastal soils as a result of the presence of calcium carbonates in the soil. The soil was generally categorized as having a sandy texture. Soil and biochar chemical characteristics are summarized in Table 1.

\subsection{Effects of Biochar on Casuarina equisetifolia Growth after Field Establishment}

3.2.1. Casuarina Height. The results of this study indicate that Casuarina height growth was significantly different with the application of different biochar rates at $6 \mathrm{MAE}, 9 \mathrm{MAE}$, and $12 \operatorname{MAE}(p<0.05,0.05$, and 0.01 , respectively) as shown in Table 2. There were no significant differences in Casuarina height with the application of different biochar rates at the third month after field establishment $(p<0.09)$. Generally, biochar-amended plots recorded higher Casuarina height than the untreated control. Biochar application rate of $7.5 \mathrm{tha}^{-1}$ recorded the highest Casuarina height at two assessment periods (6 MAE and $12 \mathrm{MAE}$ ). The increase in height compared to the control for biochar application rate
TABle 3: Coefficient of correlation between biochar application rates and mean Casuarina height at four assessment periods.

\begin{tabular}{lcc}
\hline Assessment period & Coefficient of correlation $(r)$ & $p$ value \\
\hline 3 MAE & 0.56 & 0.059 \\
$6 \mathrm{MAE}$ & 0.59 & 0.043 \\
$9 \mathrm{MAE}$ & 0.54 & 0.072 \\
$12 \mathrm{MAE}$ & 0.72 & 0.008 \\
\hline
\end{tabular}

MAE: months after field establishment.

of $7.5 \mathrm{tha}^{-1}$ was $24.3 \%$ and $20.2 \%$, respectively, for the two assessment periods. At the third month after field establishment, biochar application rate of 2.5 and $7.5 \mathrm{tha}^{-1}$ recorded similar mean height $(0.89 \mathrm{~m})$; this mean height was $18.7 \%$ higher than the control (Table 2). At 9 MAE, biochar application at $2.5 \mathrm{tha}^{-1}$ recorded the highest plant height $(2.18 \mathrm{~m})$ which was $23.2 \%$ above the control treatment.

Generally, there were no significant differences in $\mathrm{Ca}$ suarina height between the application rate of 2.5 and $7.5 \mathrm{t} \mathrm{ha}^{-1}$. At the 6- and 12-MAE assessment period when the application of biochar rate of $7.5 \mathrm{t} \mathrm{ha}^{-1}$ recorded the highest mean height, the difference in Casuarina height compared to the biochar application rate of $2.5 \mathrm{tha}^{-1}$ was only $0.7 \%$ and $2.7 \%$, respectively. Among the biochar application rates used, the application rate of $5.0 \mathrm{tha}^{-1}$ recorded lower $\mathrm{Ca}$ suarina mean height across the growth period compared to 2.5 and $7.5 \mathrm{tha}^{-1}$ application rates. However, the application of biochar at $5.0 \mathrm{tha}^{-1}$ recorded higher Casuarina mean height than the untreated control by $13.3 \%, 18.3 \%, 16.9 \%$, and $14.8 \%$ across the four assessment periods, respectively. 


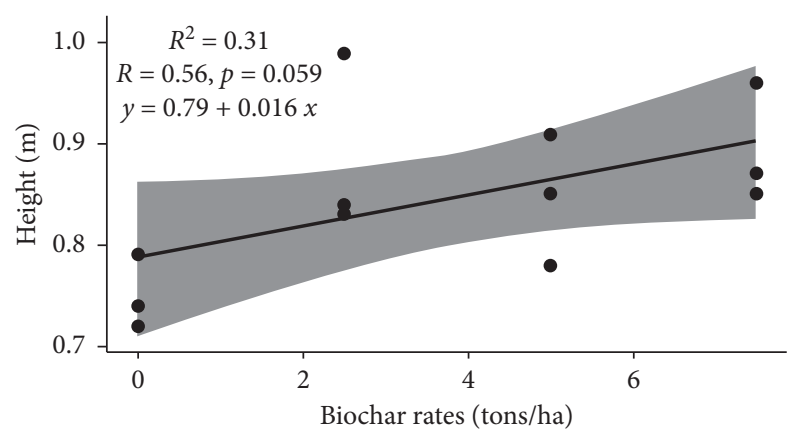

(a)

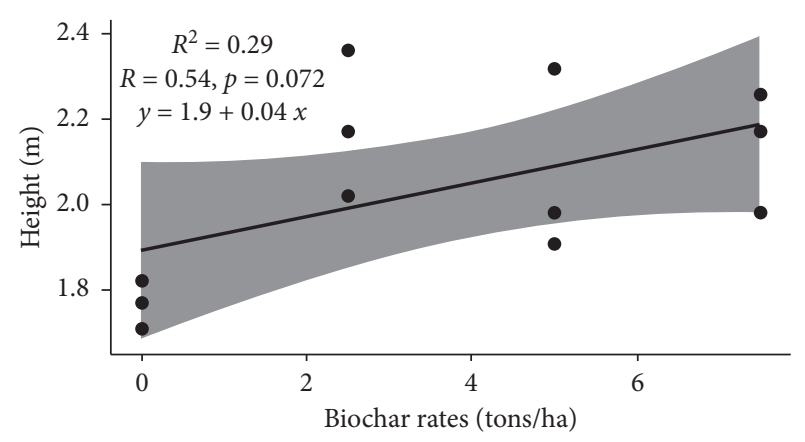

(c)

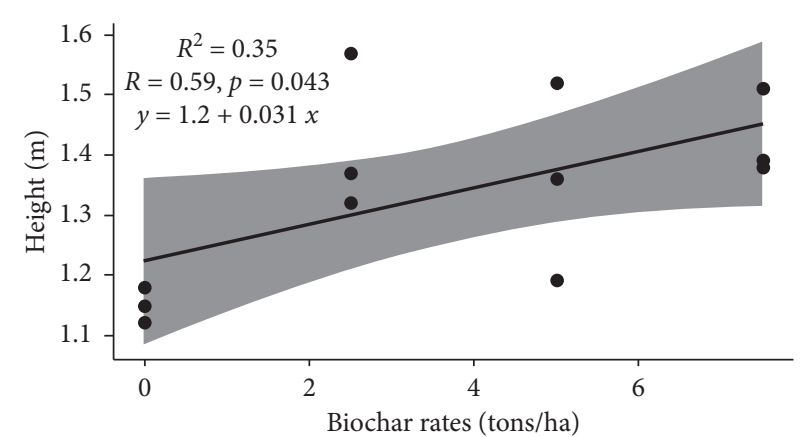

(b)

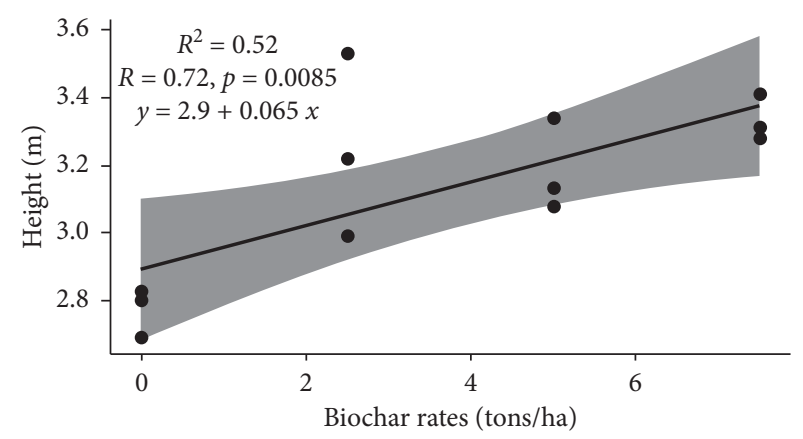

(d)

FIGURe 1: Relationship between biochar application rates and Casuarina height at different assessment periods: (a) 3 MAE, (b) 6 MAE, (c) 9 MAE, and (d) 12 MAE.

The results Pearson's correlation conducted revealed that there was a significant positive linear relationship between biochar application rates and Casuarina height growth ( $r=+0.56,+0.59,+0.54$, and +0.72 , respectively) for the four sampling periods as highlighted in Table 3 and Figure 1. The results of linear regression analyses conducted to determine the strength of association between biochar rates and mean Casuarina height show that only $29 \%$ to $51 \%\left(r^{2} * 100\right)$ of the observations made can be accounted for by changes made in the biochar application rates applied.

The increase in Casuarina height with biochar application can be attributed to enhanced plant nutrients availability such as phosphorus and potassium and improvement of soil physical properties such as reduced BD and enhanced soil moisture storage $[17,18]$. This could explain the observed trend in the present study where biochar-amended plots recorded higher Casuarina mean height than the untreated control throughout the assessment period. Studies have shown that low susceptibility of biochar to microbial processes enhance the stability of soil organic matter in the lower soil horizons while improving availability of water and nutrients to plants and decrease erosion risks $[19,20]$. However, research on the effects of biochar on tree growth is still outstanding [21]. Growth of agricultural crops as influenced by biochar application has received significant focus in the recent past with studies being conducted to evaluate the effect of biochar on yields [11, 22, 23].

To understand the effect of biochar on plant growth in general, Mohan et al. [24] reported increased eggplant growth due to biochar application as compared to the control. The study further revealed that soils amended with $3 \%$ biochar had the highest increase in both plant height and number of leaves. The study also reported that the average plant height improved from $8.3 \mathrm{~cm}$ in the first week to $20 \mathrm{~cm}$ (seventh week) versus $6.0 \mathrm{~cm}$ (first week) to $9.5 \mathrm{~cm}$ (seventh week) in case of control. Comparable results to this study on increase of plant growth as a result of biochar application were also reported by Carter et al. [25]. Biochar has been reported to promote plant productivity through several mechanisms such as enhancement of physical conditions with biochar application through enhanced water-holding capacity thereby providing water for plant growth [26].

Hafeez et al. [27] also reported significant increase in height of glycine max (L.) with biochar application. The study attributed this to alleviating the physicochemical stresses particularly water and nutrient scarcity as a result of biochar application. The findings of this study concur with the findings of Berek and Hue [28] who reported that biochar application increased plant growth and biomass by two to four folds. Drabkin and Weinfuether [29] reported that tree growth showed significant differences on sites with biochar; the study however recommended further studies to ascertain the observed trends.

3.2.2. Casuarina Diameter at Ground Level (DGL) and Diameter at Breast Height $(\mathrm{DBH})$. The effect of biochar application on Casuarina mean collar diameter, that is, "diameter at ground level of trees (DGL)" over a period of time was assessed and found as shown in Figure 2. There was 


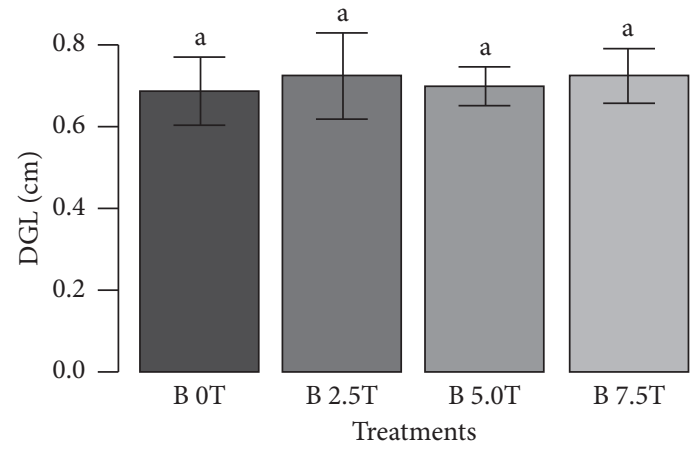

(a)

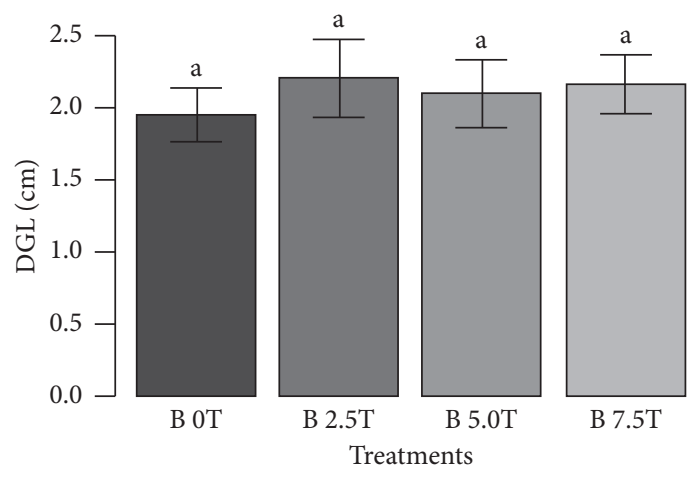

(c)

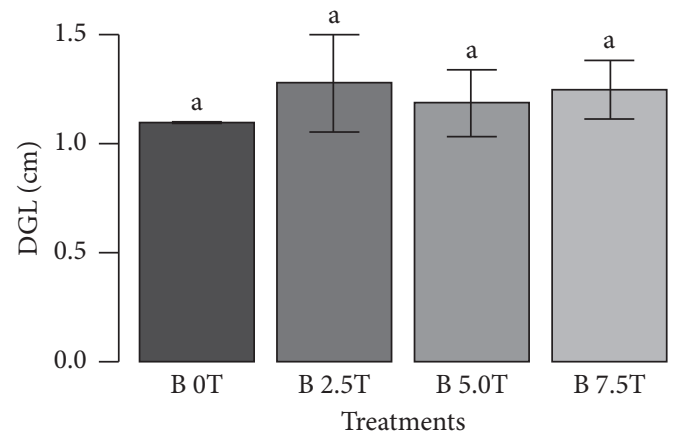

(b)

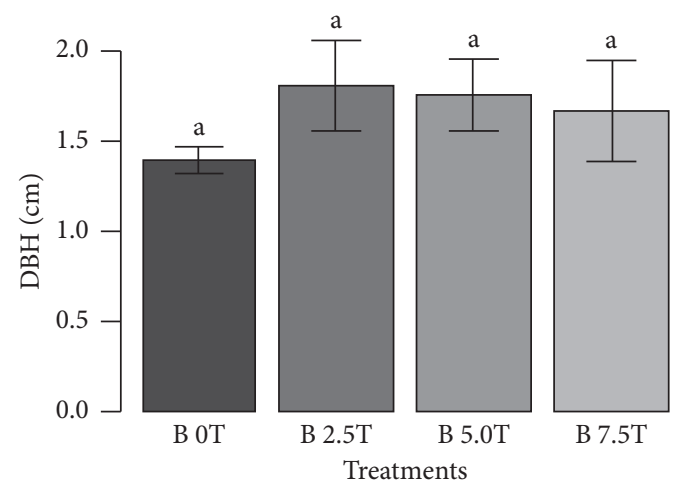

(d)

Figure 2: Casuarina DGL and DBH under different biochar application rates: (a) DGL at 3 months, (b) DGL at 6 months, (c) DGL at 9 months, and (d) DGL at 12 months. Values denoted by the same letter in each graph are not significantly different at $p<0.05$; "B" means biochar, "C" means control treatment; treatment rates are in tons/ha.

gradual increase in DGL across the four assessment periods as illustrated in Figure 2. There were, however, no significant differences in collar diameter following the application of different biochar rates across the assessment period $(p<0.91$, 0.82 , and 0.57 , respectively) for $3 \mathrm{MAE}, 6 \mathrm{MAE}$, and $9 \mathrm{MAE}$. There was also no significant difference in terms of DBH at 12 MAE assessment period $(p<0.17)$. The untreated control recorded the lowest DGL and DBH across the growth period as highlighted in Figure 2. Despite the lack of significant differences in terms of DGL and DBH after application of different biochar rates, generally, plots treated with biochar recorded higher DGL and DBH compared to the untreated control (Figure 2). The application of biochar at $2.5 \mathrm{tha}^{-1}$ recorded the highest DGL and DBH across the growth period; this was $4.3 \%, 16.4 \%, 12.8 \%$, and $30.2 \%$ above the control for the four assessment periods, respectively.

Pearson's correlation conducted to determine the existence of association between biochar application rates and Casuarina DGL/DBH revealed that there was an insignificant positive linear relationship between the two variables $(r=+0.14,+0.29,+0.28$, and +0.36 for the four sampling periods) as shown in Figure 3. The results further revealed a very weak association between biochar application rates and Casuarina DGL/DBH. Only $2 \%$ to $13 \%$ of the observations made in Casuarina DGL and DBH can be accounted for by changes in biochar application rates. This indicates that increasing biochar application rates did not lead to an increase in DGL and DBH. The increase in DGL and DBH with biochar application can be attributed to improvement of physical and chemical properties of the soil with biochar application. The influence of biochar on physical properties of soil directly affects the growth of plants through enhanced root penetration as a result of reduced $\mathrm{BD}$ and soil moisture retention due to increased porosity as a result of biochar's highly porous nature [30].

The effects of biochar on Casuarina DGL and DBH are subject to further studies. Vast majority of biochar studies are conducted on agricultural soils, and field experiments studying effect of biochar on tree growth are limited. The available literature has also reported contradicting findings. Palviainen et al. [31] reported that biochar application of $10 \mathrm{Mgha}^{-1}$ increased diameter growth of dominant trees significantly which corresponded to an increase of $25 \%$ compared to the control. Macphail [32], in his meta-analysis, reported that biochar increases plant growth by up to $41 \%$. The metaanalysis attributed the increase in plant growth after biochar application to nutrient and water retention by biochar.

\subsection{Effects of Biochar on Soil Physical Properties}

3.3.1. Soil Bulk Density (BD). Results from this study showed that there was significant difference in soil BD following application of different biochar rates at $3 \mathrm{MAE}$ and 


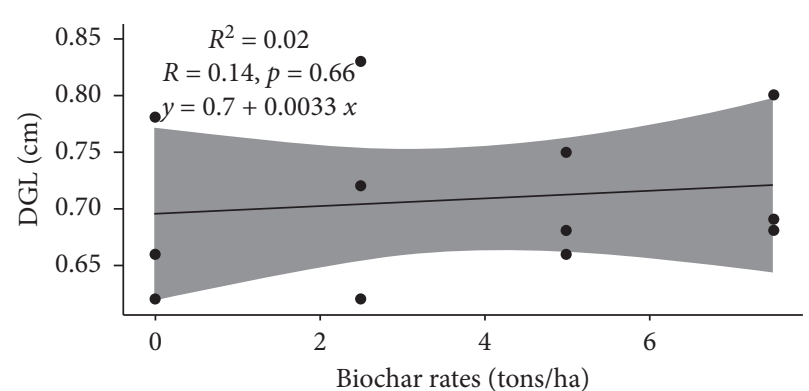

(a)

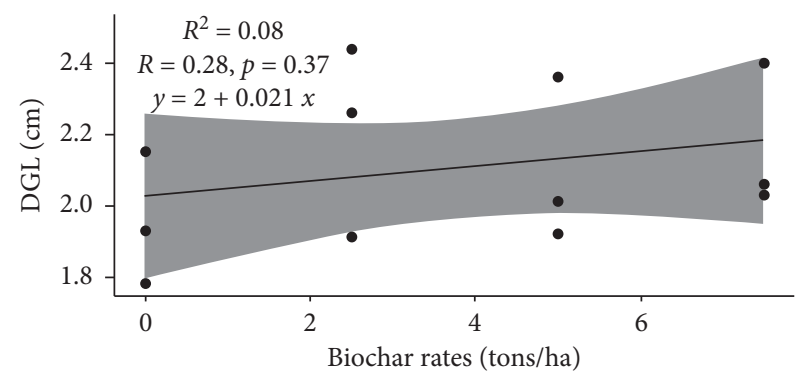

(c)

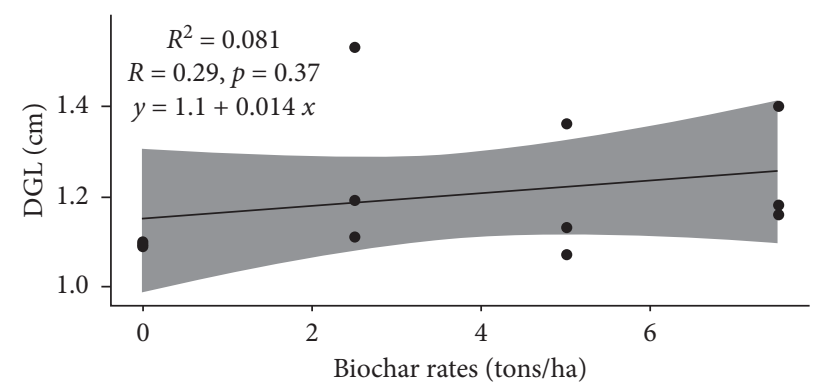

(b)

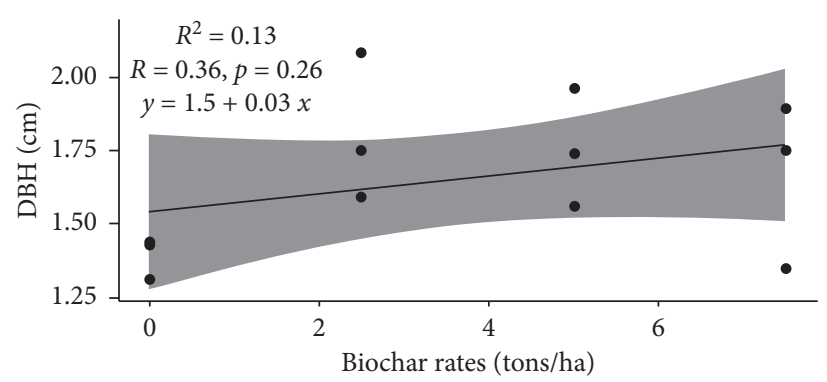

(d)

Figure 3: Relationship between biochar application rates and Casuarina DGL/DBH at different assessment periods: (a) 3 MAE, (b) 6 MAE, (c) 9 MAE, and (d) 12 MAE.

9 MAE assessment period; ( $p<0.02$ and 0.001 , respectively) for the two sampling periods as highlighted in Figure 4. Generally, there was a gradual decline in $\mathrm{BD}$ with increased rates of biochar application. Biochar application at the rate of $7.5 \mathrm{tha}^{-1}$ recorded the lowest $\mathrm{BD}$ of $0.99 \mathrm{~g} \mathrm{~cm}^{-3}$ for both sampling periods. The control treatment recorded the highest BD of between 1.29 and $1.32 \mathrm{~g} \mathrm{~cm}^{-3}$. There was a decrease in $\mathrm{BD}$ of $14.7 \%, 15.5 \%$, and $23.2 \%$ for biochar rates of $2.5,5.0$, and $7.5 \mathrm{tha}^{-1}$, respectively, compared to the control at $3 \mathrm{MAE}$ assessment period. On the contrary, there was decrease in $\mathrm{BD}$ of $15.2 \%, 17.4 \%$, and $25 \%$ for biochar rates of 2.5, 5.0, and $7.5 \mathrm{tha}^{-1}$, respectively, compared to the control at $9 \mathrm{MAE}$ assessment period. Studies have shown that biochar application reduces $\mathrm{BD}$ probably through mixing or dilution effect [33]. Studies have shown that reduction in BD with biochar application is as a result of increased soil porosity with biochar addition thus enhancing aeration and root development. Higher BD restricts root development due to soil compaction [34]. Studies have shown that biochar has a porosity of $70 \%$ to $90 \%$ thus enhancing soil porosity when mixed with the soil $[35,36]$.

The results of Pearson's correlation conducted to determine the relationship between biochar application rates and soil BD revealed a significant negative relationship $(r=-0.87$, $p<0.0003)$ for 3 MAE and $(r=-0.79, p<0.002)$ for 9 MAE as shown in Figure 5. There was a decline in soil BD with increasing rates of biochar application. This can be attributed to biochar's porous nature and low $\mathrm{BD}$ which could have lowered the soil's BD. Figure 5 also shows that there was a strong association between biochar application rates and soil BD. Between $63 \%$ and $75 \%\left(r^{2} * 100\right)$ of the observations made in soil BD can be attributed to changes made in the biochar application rates with the remaining $25 \%$ to $37 \%$ attributed to other environmental factors not under study.

$\mathrm{BD}$ is an indicator of soil compaction and soil health. It affects infiltration, rooting depth, available water capacity, soil porosity, plant nutrient availability, and soil microorganism activity [37]. A study by $\mathrm{Ma}$ et al. [38] revealed that soil $\mathrm{BD}$ is dependent on soil organic matter, texture, and the density of the mineral soil. Most studies have reported a decrease in $\mathrm{BD}$ following biochar application $[23,35,39,40]$. Humberto [33] reported a decrease of BD by $3 \%$ to $31 \%$ with biochar addition. According to Oshunsanya and Aliku [40], the decrease in $\mathrm{BD}$ of biochar-amended soils could be an indicator of soil structure, aggregation, and aeration. Omondi et al. [41] also reported a decrease in BD by $7.6 \%$ following biochar addition. The study further revealed that soil $\mathrm{BD}$ decreased with the increasing amount of biochar applied; the same trend was observed in this study as shown in Figure 5. Studies have also shown that biochar can reduce $\mathrm{BD}$ in coarse textured soils more than fine textured soils, this could explain the trend observed in this study which was dominated by sandy soils. This is estimated at $14.2 \%$ in course textures soils and $9.2 \%$ in fine textured soils [41]. Hseu et al. [42] reported a reduction in BD from $1.5 \mathrm{mg} \mathrm{m}^{-3}$ in the control to $1.4 \mathrm{mg} \mathrm{m}^{-3}$ in biochar-treated soils; the plots with $10 \%$ biochar recorded a reduction in $\mathrm{BD}$ of up to $25 \%$ compared to the control. The decrease in BD following biochar application may also be as a result of biochar's lower BD $\left(0.63 \mathrm{~g} \mathrm{~cm}^{-3}\right)$ than soil $\left(1.25 \mathrm{~g} \mathrm{~cm}^{-3}\right)$. Biochar is highly porous and its application to soils can improve soil physical properties, such as soil porosity, $\mathrm{BD}$, pore size distribution, water-holding capacity, infiltration, and hydraulic conductivity [43]. 


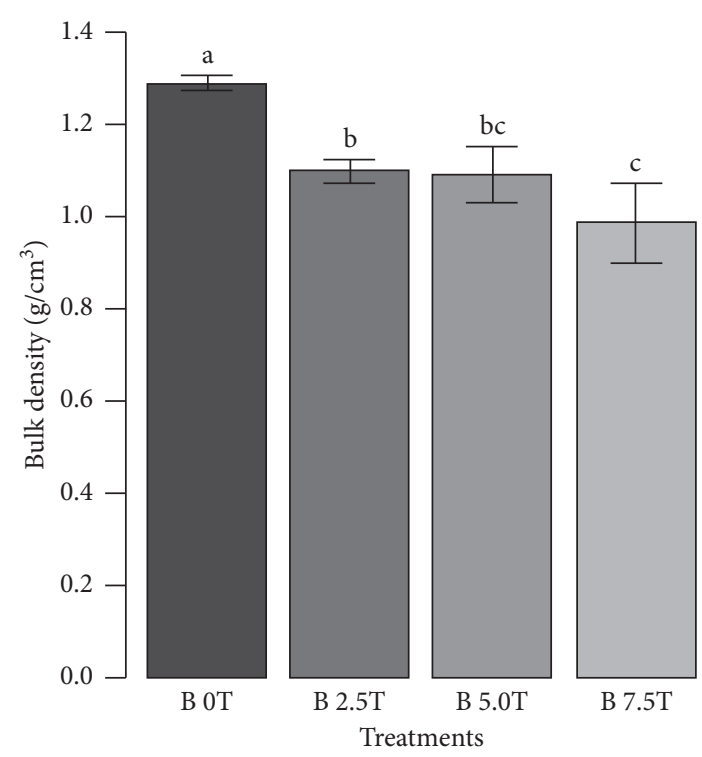

(a)

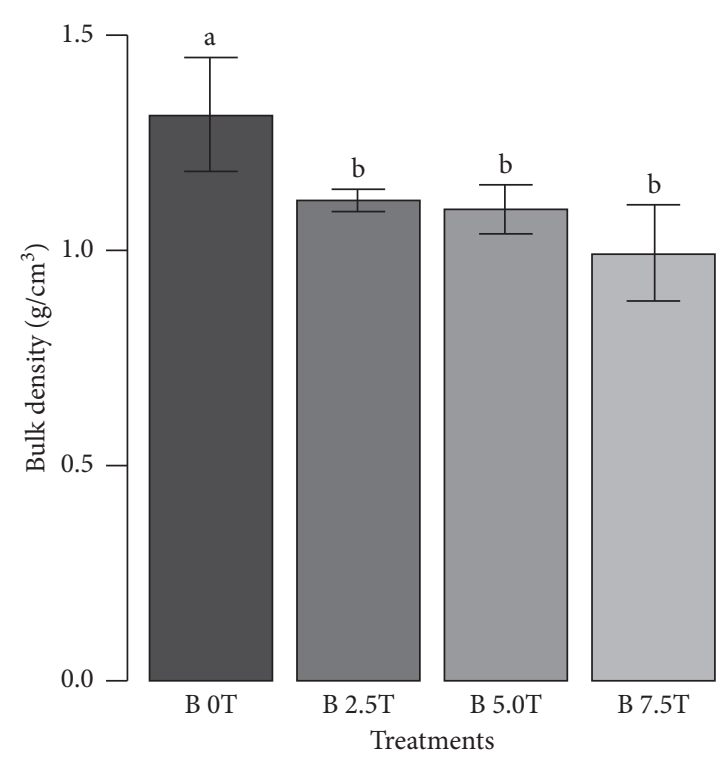

(b)

FIGURE 4: Soil bulk density as influenced by biochar application at two assessment periods: (a) bulk density at 3 months and (b) bulk density at 9 months. Values denoted by the same letter in each graph are not significantly different at $p<0.05$; "B" means biochar, "T" means biochar rates in tons/ha.

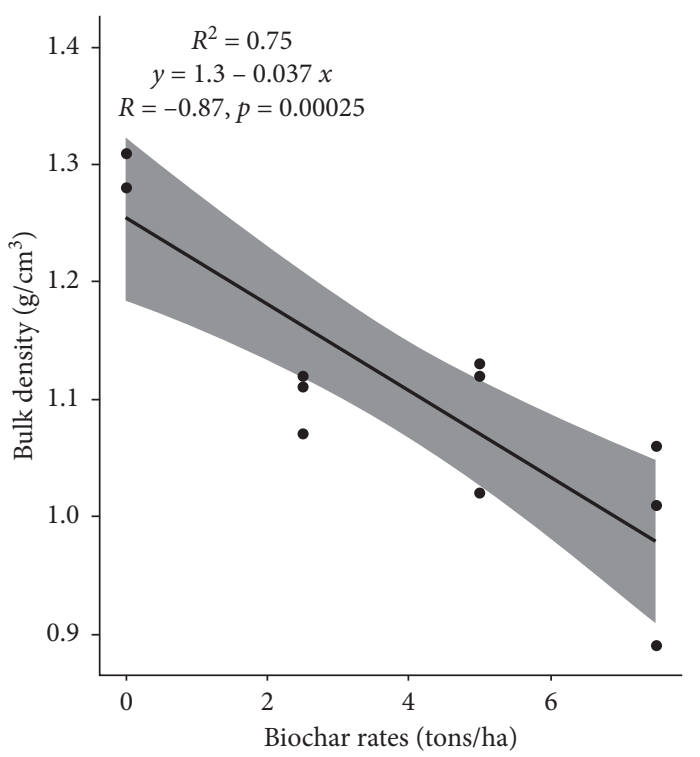

(a)

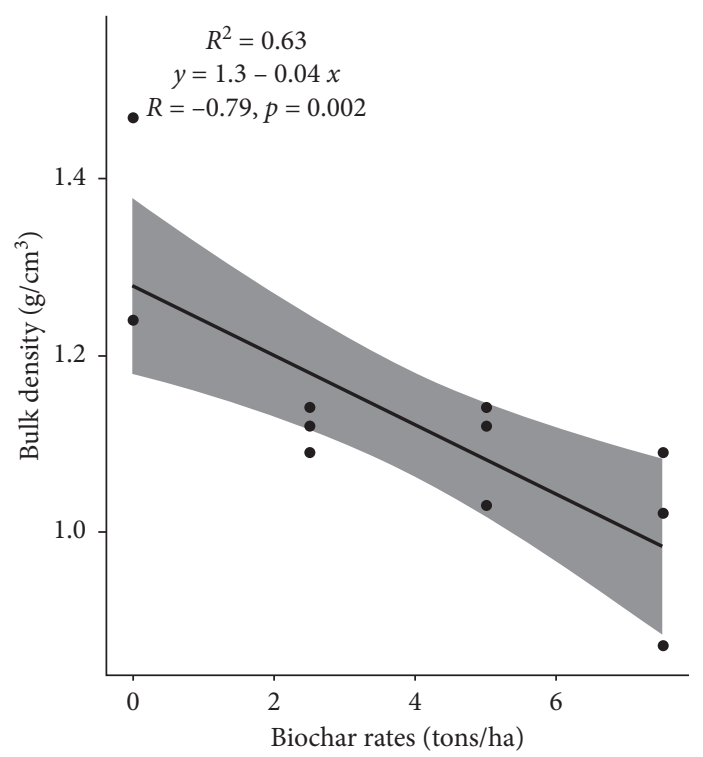

(b)

FIGURE 5: Relationship between biochar application rates and soil bulk density at different assessment periods: (a) 3 MAE and (b) 9 MAE.

3.3.2. Soil Moisture Content. There were significant differences in soil moisture content following application of different biochar rates $(p=0.0000006, p=0.0004$, $p=0.000007$, and $p=0.0001$ for $3 \mathrm{MAE}, 6 \mathrm{MAE}, 9 \mathrm{MAE}$, and 12 MAE, respectively) as shown in Figure 6. Biochar application rate of $7.5 \mathrm{tha}^{-1}$ recorded the highest soil moisture content across the four sampling periods. Generally, biochar-amended plots recorded higher soil moisture content than the control. There was increase in soil moisture content of up to $67.6 \%$ at $3 \mathrm{MAE}, 77 \%$ at $6 \mathrm{MAE}, 94.1 \% 9$
MAE, and $108 \%$ at 12 MAE with the application of biochar at $7.5 \mathrm{tha}^{-1}$ compared to the control treatment. The increase in soil moisture content with biochar application can be attributed to biochar's porous nature and large surface area which enables retention of water in the soil pores and rise of water from lower soil horizons through capillary action [44]. Similar findings were also reported by [45], who observed an increase in soil moisture content in sandy soils with biochar application. Biochar has large surface area which enhances the adsorptive capacity of soil while improving its pore size 


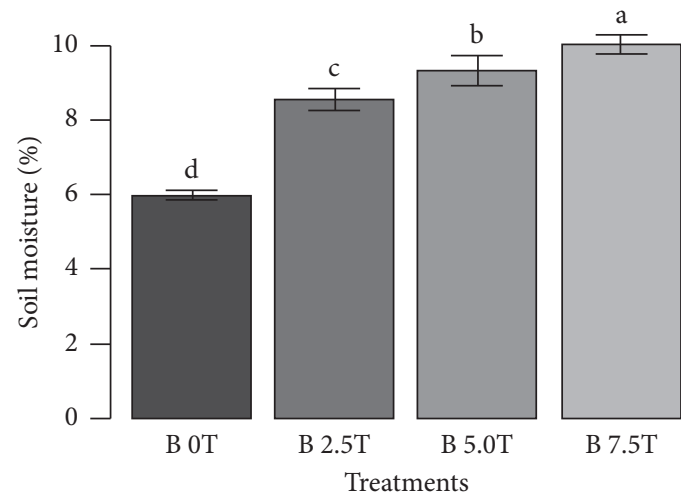

(a)

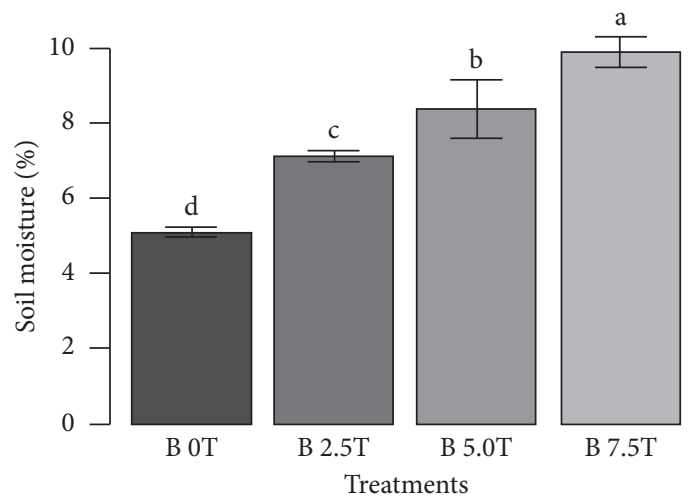

(c)

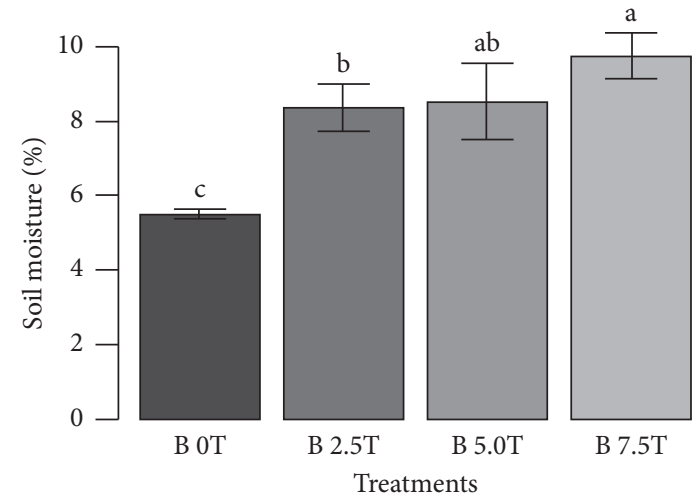

(b)

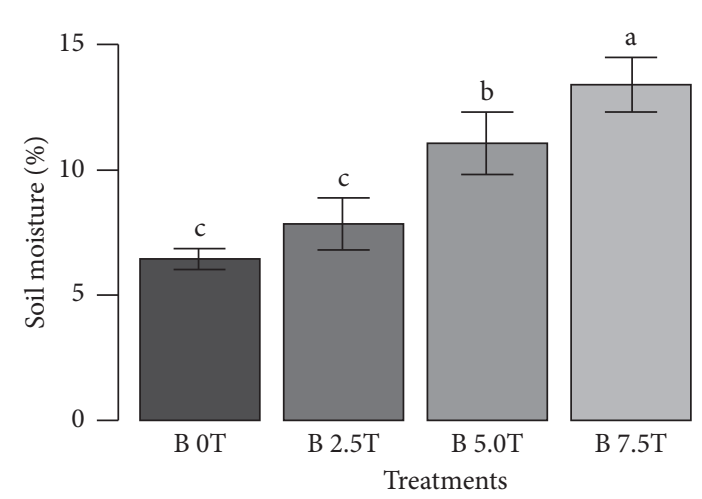

(d)

FiguRE 6: Soil moisture content under different biochar application rates at different assessment periods: (a) soil moisture at 3 months, (b) soil moisture at 6 months, (c) soil moisture at 9 months, and (d) soil moisture at 12 months. Values denoted by the same letter in each graph are not significantly different at $p<0.05$, "B" means biochar, and "T" means biochar rates in tons/ha.

distribution, $\mathrm{BD}$, and consequently leading to an increase in available soil moisture crucial for plant growth and development. In addition, there exist a strong direct relationship between biochar's surface area and the pore volume of the soil $[46,47]$.

Figure 7 shows that there was a significant positive linear relationship between biochar application rates at soil moisture content at the four sampling periods $(r=0.93,0.87$, 0.97 , and 0.95 ), respectively, for the four assessment periods. The results of this study further revealed a strong association between biochar application rates and soil moisture content as shown in Figure 7; between $76 \%$ and $95 \%$ of observations made in the soil moisture can be attributed to changes in the biochar application rates with $5 \%$ to $24 \%$ of the observation made attributed to other environmental factors. This study shows that soil moisture content increased with increasing biochar application rates. This shows that biochar porosity and surface area also increased as biochar application rates were increased.

This study further revealed that there was a significant positive linear relationship between soil moisture content and Casuarina height across the four assessment periods as seen in Figure $8(r=0.69,0.85,0.64$, and 0.56$)$ at 3 MAE, 6 MAE, $9 \mathrm{MAE}$, and $12 \mathrm{MAE}$, respectively. Casuarina height increased with increased soil moisture content. The study further revealed that between $32 \%$ and $72 \%$ of observation made in Casuarina height growth can be attributed to changes in soil moisture content across the assessment periods. However, there was no significant association between soil moisture and Casuarina DGL and DBH across the four assessment periods as shown in Figure 9. Only 3\% to $33 \%$ of the observations made Casuarina DGL and DBH can be attributed to changes in soil moisture following biochar application with $67 \%$ to $97 \%$ of the observations attributed to other factors not under study. The lack of a strong association between soil moisture content and Casuarina DGL and $\mathrm{DBH}$ is subject for further studies.

Many studies have reported positive effects of biochar on soil moisture [11, 48, 49]. A study by Pühringer [11] conducted in Siaya (Kenya) reported a slight increase in soil moisture content with increasing biochar rates. The study reported a substantial difference in soil moisture for biochar rates of 10 and $5 \mathrm{tha}^{-1}$ compared to the untreated control. Wilson and Major [48] also reported an increase in soil moisture content in a sandy loam soil following biochar application; the soil moisture in biochar-treated plots was $18 \%$ higher than the control. The capacity of biochar to enhance soil moisture retention has been attributed to numerous factors. According to Carvalho et al. [7], biochar's high total porosity is an attribute that enables it to retain 


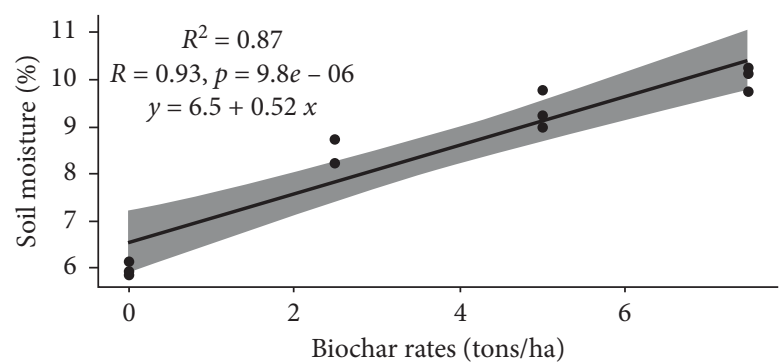

(a)

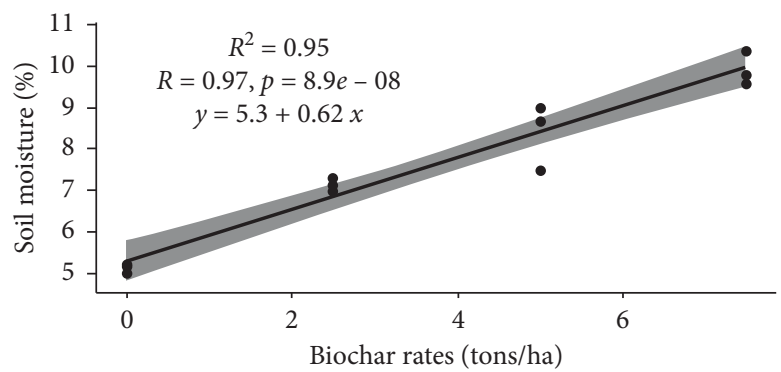

(c)

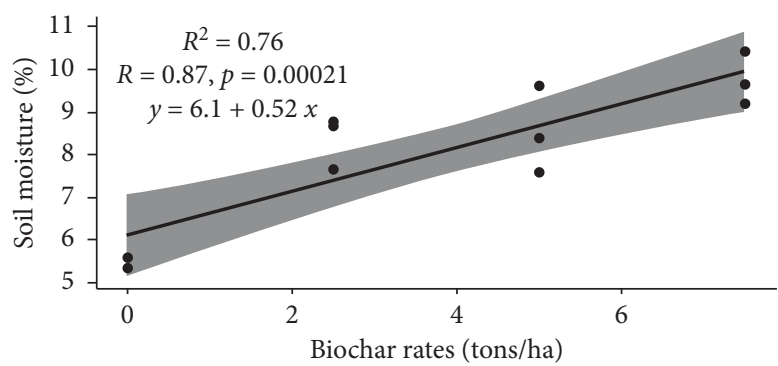

(b)

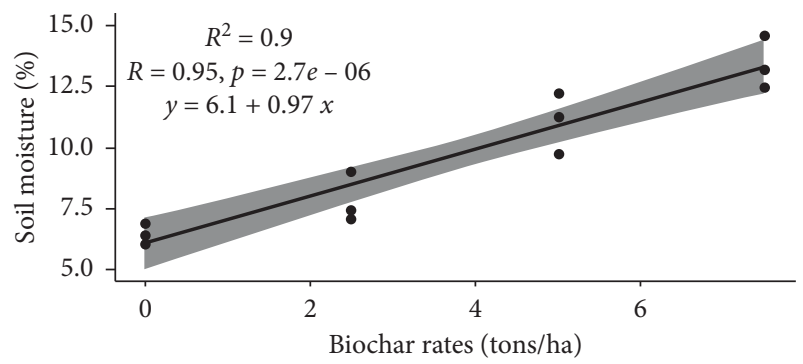

(d)

FIGURE 7: Relationship between biochar application rates and soil moisture content at different assessment periods: (a) 3 MAE, (b) 6 MAE, (c) 9 MAE, and (d) 12 MAE.

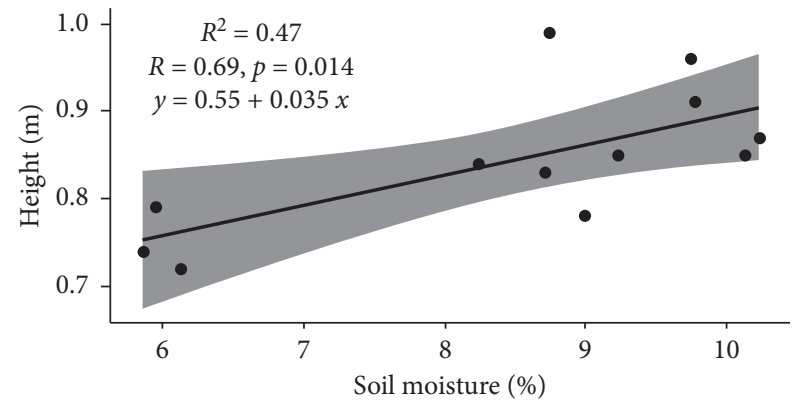

(a)

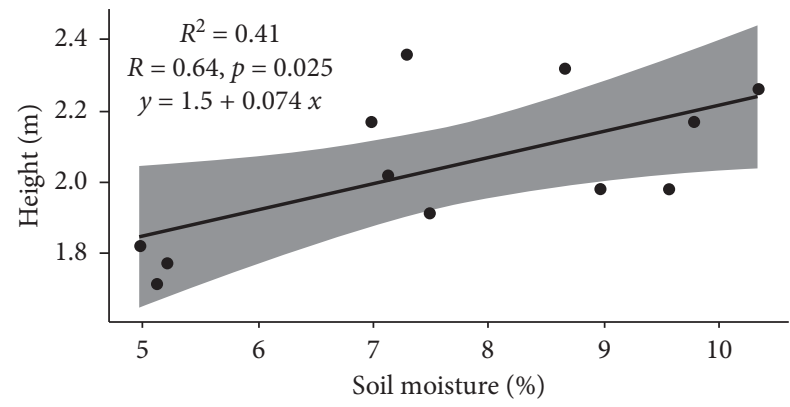

(c)

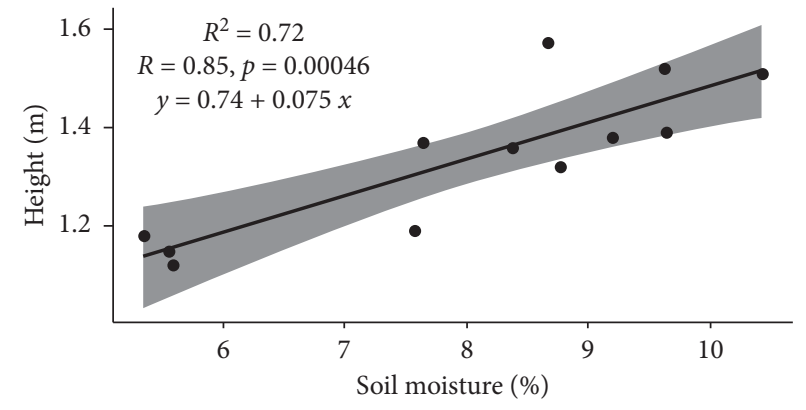

(b)

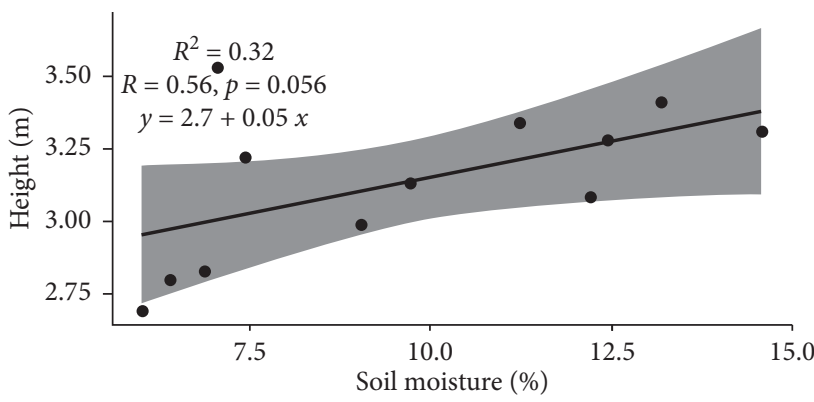

(d)

FIGURE 8: Relationship between soil moisture and Casuarina height at different assessment periods: (a) 3 MAE, (b) 6 MAE, (c) 9 MAE, and (d) 12 MAE. 


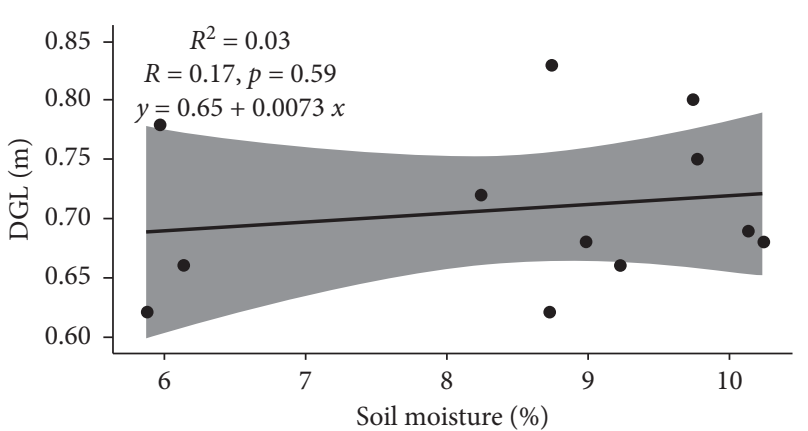

(a)

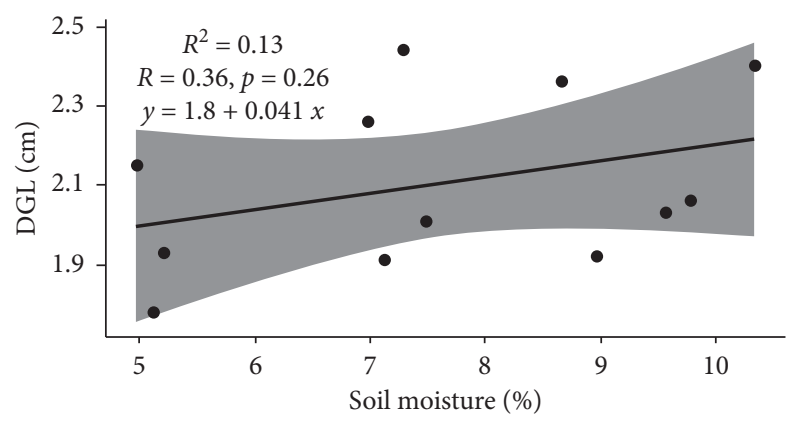

(c)

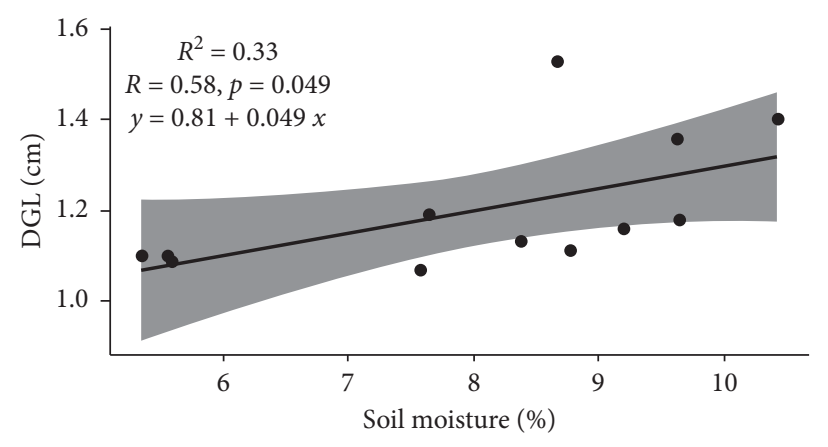

(b)

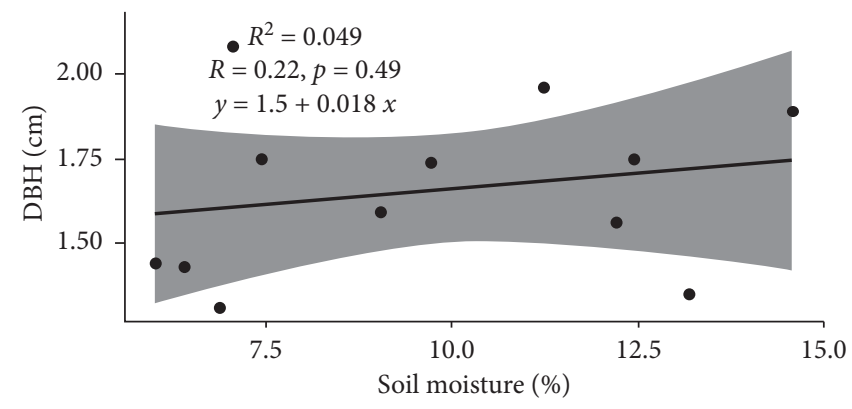

(d)

FIGURE 9: Relationship between soil moisture and Casuarina DGL/DBH at different assessment periods: (a) 3 MAE, (b) 6 MAE, (c) 9 MAE, and (d) 12 MAE; $n=12$.

water in small pores and thus increase water-holding capacity and assist water to rise from lower soil horizons to the topsoil through capillary rise after heavy rains. In a study by Åslund [50], soil water content at field capacity was significantly higher after the additions of biochar than control treatment. A study by Novak et al. [49] concluded that generally biochar amendments enhance soil moisture storage. However, Åslund [50] further noted that the soil moisture enhancement depends on biochar material used and pyrolysis temperature used during biochar production. The study also noted that sandy soils retained more moisture despite their coarse texture. Novak et al. [49] also reported improvement of soil moisture storage in two silt loams ranging between 0.5 and $0.8 \mathrm{~cm}$ of water per $15 \mathrm{~cm}$ soil depth.

\section{Conclusion and Recommendations}

The aim of the study was to determine the effect of biochar on Casuarina equisetifolia growth and soil physical properties (soil moisture content and BD). The results of this study stipulate that biochar has the potential to enhance Casuarina growth. Biochar increased Casuarina height by up to $24.3 \%$ with biochar application rate of $7.5 \mathrm{tha}{ }^{-1}$ compared to the untreated control. Generally, all plots treated with biochar recorded higher Casuarina height and DGL compared to the control. Biochar application also significantly influenced soil $\mathrm{BD}$ and soil moisture content. Biochar application significantly lowered soil BD; there was a decrease in $\mathrm{BD}$ of up to $25 \%$ after biochar application. The results from this research show that the use of biochar can assist reduced soil compaction through its effect on soil BD. Reduction of soil compaction will thus enhance root development thereby enhancing tree growth. The findings of this study also show that biochar application can alleviate soil moisture stress in farmlands. Plots treated with biochar recorded higher soil moisture than the untreated control. Biochar application rate of $7.5 \mathrm{tha}^{-1}$ recorded the highest soil moisture content across the four sampling periods. Generally, biochar-amended plots recorded higher soil moisture content than the control. The increase in soil moisture content with biochar application can be attributed to biochar's porous nature and large surface area. The results also showed a significant positive linear relationship between biochar application rates and soil moisture content and Casuarina mean height. There was, however, a significant negative correlation between biochar application rates and soil $\mathrm{BD}$. Biochar application has the potential of enhancing Casuarina growth (DGL, DBH, and height) through improvement of soil physical properties which play a key role in plant growth and development. Based on the results, it is recommended that farmers at the coastal region of Kenya incorporate biochar during Casuarina woodlot establishment to reduce soil compaction through reduced soil BD and enhance soil moisture storage which will enhance Casuarina growth.

\section{Data Availability}

The data that support the findings of this study are available from the corresponding author upon reasonable request. 


\section{Disclosure}

The authors declare that this is an original article which has not been published before and is not under consideration in another journal.

\section{Conflicts of Interest}

The authors declare that there are no conflicts of interest.

\section{Acknowledgments}

The authors would like to express their gratitude to Kenya Forestry Research Institute for financing the research and to all KEFRI Gede staff who contributed towards the success of the study.

\section{References}

[1] P. Drechsel, D. Gyiele, and O. Cofie, "Population density, soil nutrient depletion, and economic growth in sub-Saharan Africa," Ecological Economics, vol. 38, no. 2, pp. 251-258, 2001.

[2] F. Muriu, J. Kung'u, R. Karega, J. Njuki, M. Mucheru-Muna, and D. Mugendi, "Adoption of nutrient replenishment technologies by farmers in Kirege sub-location of Central Kenya," African Crop Science Proceedings, vol. 7, pp. 15011505, 2005.

[3] H. Julio and B. Carlos, Agricultural Production and Soil Nutrient Mining in Africa: Implication for Resource Conservation and Policy Development, International Centre for Soil Fertility and Agriculture Development, Montgomery, AL, USA, 2006.

[4] J. Ochieng, L. Kirimi, and M. Mathenge, "Effects of climate variability and change on agricultural production: the case of small scale farmers in Kenya," NJAS-Wageningen Journal of Life Sciences, vol. 77, pp. 71-78, 2016.

[5] M. Herrero, C. Ringler, J. van de Steeg et al., Climate Variability and Climate Change and Their Impacts on Kenya's Agricultural Sector, ILRI, Nairobi, Kenya, 2010.

[6] A. W. Imoro, M. Sackey, and A. H. Abubakari, "Preliminary study on the effects on the effects of two different sources of organic manure on the growth performance on Moringa oleifera," Journal of Biology, Agriculture and Healthcare, vol. 2, no. 10, pp. $147-158,2012$.

[7] M. T. M. Carvalho, B. E. Madari, L. Bastiaans, P. A. J. Oort, A. B. Heinemann, and H. Meinke, "Biochar improves fertility of clay soil in Brazilian Savannah: short yerm effects and impacts on rice yield," Journal of Agriculture and Rural Development in the Tropics and Subtropics, vol. 114, no. 2, pp. 101-107, 2013.

[8] I. Baidoo, D. B. Sarpong, and S. Bolwig, "Biochar amended soils and crop productivity: a critical and metaanalysis of literature," International Journal of Development and Sustainability, vol. 5, no. 9, pp. 414-432, 2016.

[9] M. Videgain-Marco, P. Marco-Montori, C. Martí-Dalmau, M. d. C. Jaizme-Vega, J. J. Manyà-Cervelló, and F. J. GarcíaRamos, "Effects of biochar application in a sorghum crop under greenhouse conditions: growth parameters and physicochemical fertility," Agronomy, vol. 10, no. 1, p. 104, 2019.

[10] M. M. Al-Wasfy and A. S. El-Khawaga, "Effect of organic fertilizer on growth yield and fruit quality of Zaghloul date palm growing in sandy soil," Assiut Journal of Agricultural Sciences, vol. 39, no. 1, pp. 121-133, 2008.
[11] H. Pühringer, "Effects of different biochar application rates on soil fertility and retention in on-farm experiments on smallholder farms in Kenya," Master's thesis, Swedish University of Agricultural Sciences, Uppsala, Sweden, 2016.

[12] T. O. A. Adeyemi and O. O. Idowu, "Biochar. Promoting crop yield, improving soil fertility, mitigating climate change and restoring polluted soils," World News of Natural Sciences, vol. 8, pp. 27-36, 2017.

[13] http://www.kilifi.go.ke.

[14] L. Krotz, L. Ragaglia, and G. Giazzi, Quick, Accurate Nitrogen, Total Carbon and Total Organic Carbon Determination in Soils by Elemental Analysis, Strada, Milano, Italy, 2013.

[15] J. R. Okalebo, W. G. Kenneth, and P. L. Woomer, Laboratory Method of Soil and Plant Analysis, SACRED Office, Nairobi, Kenya, Second edition, 2002.

[16] U. M. Riziki, M. Benson, and D. Benjamin, "Effects of biochar and manure on soil properties and growth of Casuarina equisetifolia seedlings at the coastal region of Kenya," Scientific Research and Essays, vol. 15, no. 3, pp. 52-63, 2020.

[17] R. Helliwell, "Effect of biochar on plant growth," Arboricultural Journal, vol. 37, no. 4, pp. 238-242, 2015.

[18] T. Berihun, S. Tolosa, M. Tadele, and F. Kabede, "Effect of biochar application on growth of garden pea (Pisum sativum L.) in acidic soils of Bule Woreda Gedeo zone, Southern Ethiopia," International Journal of Agronomy, vol. 2017, Article ID 6827323, 8 pages, 2017.

[19] K. E. Brantley, K. R. Brye, M. C. Savin, and D. E. Longer, "Biochar source and application rate effects on soil water retention determined using wetting curves," Open Journal of Soil Science, vol. 5, no. 1, pp. 1-10, 2015.

[20] Technology Exchange Lab (Tel), Biochar Production and Application. Geology and Energy Organization, Cambridge Innovation Centre, Cambridge, MA, USA, 2018.

[21] K. Wilson, Biochar for Forest Restoration in Western United States, Wilson Biochar Associates, South Umpqua Rural Community Partnership (SURCP), Tiller, OR, USA, 2015, http://www.wilsonbiochar.com.

[22] R. Poitras and S. Straubing, "The effect of biochar applications on soil fertility and crop production for small farms in Northeast US," Northeast Biochar Symposium, vol. 13, 2009.

[23] G. Harder, Biochars as a beneficial soil amendment in sandy soils, Ph.D. thesis, Justus- Liebig- University, Griessen, Germany, 2017.

[24] D. Mohan, K. Abhishek, A. Sarswat, M. Patel, P. Singh, and C. U. Pittman, "Biochar production and applications in soil fertility and carbon sequestration-a sustainable solution to crop-residue burning in India," RSC Advances, vol. 8, no. 1, pp. 508-520, 2018.

[25] S. Carter, S. Shackley, S. Sohi, T. Suy, and S. Haefele, “The impact of biochar application on soil properties and plant growth of pot grown Lettuce (Lactuca sativa) and cabbage (Brassica chinensis)," Agronomy, vol. 3, no. 2, pp. 404-418, 2013.

[26] B. Khaitov, H. J. Yun, Y. Lee et al., "Impact of organic manure on growth, nutrient content and yield of chilli pepper under various temperature environments," International Journal of Environmental Research and Public Health, vol. 16, no. 17, p. 3031, 2019.

[27] Y. Hafeez, S. Iqbal, K. Jabee, S. Shahza, S. Jahan, and F. Rasul, "Effect of biochar application on seed germination and seedling growth of glycine max (L) MERR. under drought stress," Pakstan Journal of Botany, vol. 49, no. 51, pp. 7-13, 2017.

[28] A. K. Berek and N. Hue, "Improving soil productivity with biochars," in Proceedings of the Improving Soil Productivity 
with Biochar, Conference, ICGAI, Yogyakarta, Indonesia, 2013.

[29] D. Drabkin and K. Weinfuether, "Effects of biochar substrates on tree growth and soil on wind throw areas and Christmas tree cultures," in The Earth Living Skin: Soil, Life and Climate ChangeECTU-SSS Conference, Bari, Italy, 2014.

[30] J. Rawat, J. Saxena, and P. Sanwal, "Biochar: a sustainable approach for improving plant growth and soil properties," Biochar - An Imperative Amendment for Soil and the Environment, 2019.

[31] M. Palviainen, H. Aaltonen, A. Laurén et al., "Biochar amendment increases tree growth in nutrient-poor, young Scots pine stands in Finland," Forest Ecology and Management, vol. 474, no. 118362, 2018.

[32] J. Macphail, "Biochar's impact on tree growth," 2018, https://www. carbongold.com/biochars-impact-on-tree-growth/.

[33] B.-C. Humberto, "Biochar and soil physical properties," Soil Science Society of America Journal, vol. 81, pp. 687-711, 2017.

[34] D. J. Kormanek, J. Banach, and P. Sowa, "Effect of soil bulk density on forest tree seedlings," International Agrophysics, vol. 29, pp. 67-74, 2015.

[35] Z. Aslam, M. Khalid, and M. Am, "Impact of biochar on soil physical properties," Schorlarly Journal of Agricultural Science, vol. 4, no. 5, pp. 280-284, 2014.

[36] K. S. Are, "Biochar and soil physical health," 2020, https://www. intechopen.com/books/biochar-an-imperative-amendment-forsoil-and-the-environment/biochar-and-soil-physical-health.

[37] USDA, "Soil bulk density," 2020, https://www.nrcs.usda.gov/ Internet/FSE_DOCUMENTS/nrcs142p2_053256.pdf.

[38] N. Ma, L. Zhang, Y. Zhang et al., "Biochar improves soil aggregate stability and water availability in a mollisol after three years of field application," PLoS One, vol. 11, no. 5, Article ID e0154091, 2016.

[39] J. Lane, An Overview of Current Biochar and Activated Carbon Markets, McLaughlin $\mathrm{H}$ Lee Enterprise Consulting Inc, Sherwood, AR, USA, 2016, https://www.biofuelsdigest.com/ bdigest/2016/10/11/an-overview-of-the-current-biocharand-activated-carbon-markets/.

[40] S. O. Oshunsanya and O. O. Aliku, "Biochar Technology for Sustainable Organic Farming," in Organic Farming- A Promising Way of Food Production, P. Konvalina, Ed., vol. 1, no. 6, pp. 111-129, Intech, London, UK, 2016.

[41] M. O. Omondi, X. Xia, A. Nahayo, X. Liu, P. K. Korai, and G. Pan, "Quantification of biochar effects on soil hydrological properties using meta-analysis of literature data," Geoderma, vol. 274, pp. 28-34, 2016.

[42] Z. Y. Hseu, S.-H. Jieni, W.-H. Chien, and R.-C. Liou, "Impacts of biochar on physical properties and erosion potential of muclstone slopeland soil," The Scientific World Journal, vol. 2014, Article ID 602197, 10 pages, 2014.

[43] D. S. Page-Dumroese, M. D. Coleman, and S. C. Thomas, "Opportunities and Uses of Biochar on Forest Soils of North America," in Biochar: A Regional Supply Chain Approach in View of Climate Change Mitigation, V. Bruckman, E. Apaydin Varol, B. Uzun, and J. Liu, Eds., pp. 315-335, Cambridge University Press, Cambridge, UK, 2016.

[44] M. Hardie, B. Clothier, S. Bound, G. Oliver, and D. Close, "Does biochar influence soil physical properties and soil water availability?" Plant and Soil, vol. 376, no. 1-2, pp. 347-361, 2014.

[45] A. S. Basso, F. E. Miguez, D. A. Laird, R. Horton, and M. Westgate, "Assessing potential of biochar for increasing water-holding capacity of sandy soils," GCB Bioenergy, vol. 5, no. 2, pp. 132-143, 2013.
[46] W. Mekura and A. Noble, "The role of biochar in ameliorating disturbed soils and sequestering soil carbon in tropical production systems," Applied and Environmental Soil Science, vol. 2013, Article ID 354965, 10 pages, 2013.

[47] L. Fayong, X. Liang, C. Niyungeko, T. Sun, F. Liu, and Y. Arai, "Effects of biochar amendments on soil phosphorus transformations in agricultural soils," Advances in Agronomy, vol. 158, pp. 131-172, 2019.

[48] K. Wilson and J. Major, "Impact of biochar on soil moisture," International Biochar Initiative, 2010.

[49] J. M. Novak, W. J. Busscher, D. W. Watts et al., "Biochars impact on soil-moisture storage in an ultisol and two aridisols," Soil Science, vol. 177, no. 5, pp. 310-320, 2012.

[50] I. Åslund, "Effects of applying biochar to soils from Embueffects on crop residue decomposition and soil fertility under varying soil moisture levels," in Agricultural Programme-Soil and Plant ScienceSwedish University of Agricultural Science, Uppsala, Sweden, 2012. 